\title{
Comparing the visual perception and aesthetic evaluation of natural landscapes in Russia and Japan: cultural and environmental factors
}

\author{
Elena G Petrova ${ }^{1 *}$, Yury V Mironov ${ }^{2}$, Yoji Aoki ${ }^{8}$, Hajime Matsushima ${ }^{3}$, Satoshi Ebine ${ }^{3}$, Katsunori Furuya ${ }^{4}$,
} Anastasia Petrova ${ }^{5}$, Norimasa Takayama ${ }^{6}$ and Hirofumi Ueda ${ }^{7}$

\begin{abstract}
Japan and Russia have deeply rooted cultural traditions regarding natural landscape appreciation, share a common border, and have areas with similar natural environments. They differ, however, in cultural, historical, and economic aspects. The purpose of this study was to reveal the similarities and differences between Russian and Japanese respondents regarding the visual and emotional evaluation of landscapes based on ethno-cultural and regional differences. We asked respondents at universities in Russia (Moscow, Irkutsk, and Kamchatka) and Japan (Hokkaido, Chiba, and Miyazaki) to group and rate 70 landscape images. Unlike theoretical concepts that explain landscape preferences within an evolutionary framework or according to individual and cultural differences, we found that these factors interact in more complicated ways. Cultural traditions and features of the natural environment that were familiar to respondents influenced their visual perception and aesthetic evaluation of landscape. Russian respondents seemed more emotional while Japanese respondents tended to be more restrained in their assessments. However, there was a strong correlation between their estimates of landscape attractiveness, which might confirm the existence of universal human concepts of landscape aesthetics. The most attractive for both Russian and Japanese respondents were waterfalls, mountains, and lakes; waterless plains were the least attractive. At the same time, we found cross-cultural differences in assessing seacoasts, rivers, forests, and swampy plains. There was practically no correlation between Russian and Japanese respondents in their appreciation of exotic/familiar landscapes. For the Russian respondents, the most exotic landscapes were also the most attractive, although we did not observe such a tendency for the Japanese. All respondents appreciated certain familiar landscapes that were symbols of native nature as very attractive. Unlike 'geoscientific' landscape classifications, in the visual and emotional grouping of landscapes, the most important feature appeared to be the presence/absence of water and the type of water basin (river, lake, and sea); for Russian respondents (especially Muscovites), topography was also important, while the Japanese respondents mostly used visual and seasonal characteristics in their classifications. All Japanese respondents assessed the attractiveness and exoticism of landscapes almost identically, while there were some differences among Russian respondents from different regions.
\end{abstract}

Keywords: Visual landscape classification; Aesthetic evaluation; Attractive landscape; Exotic landscape; Traditional landscape appreciation; Influence of natural environment

\footnotetext{
* Correspondence: epgeo@mail.ru

${ }^{1}$ Faculty of Geography, Lomonosov Moscow State University, GSP-1,

Leninskie Gory, Moscow 119991, Russia

Full list of author information is available at the end of the article
} 


\section{Background}

Current urbanization and economic development that lead to increases in industrial, transport, agricultural, recreational, and other man-made loadings on our natural environment threaten natural landscapes at different levels, from local to global. When selecting landscapes for special care and conservation, we should consider not only the objective assessment of their qualities, significance, and usefulness - that is, their ecological, economic, and social value - but also their aesthetic originality since it is very important to preserve aesthetically valuable landscapes for future generations. For example, the scenic beauty and high aesthetic value of the landscape is one of the key prerequisites for assigning National Park status to a given area (IUCN - International Union for Conservation of Nature 1969).

In recent decades, many studies devoted to the psychological and aesthetic evaluation of landscapes have been published (Aoki 1999, 2007). Nevertheless, the concept of landscape appreciation has yet to be clearly defined and there is a lack of agreement on evaluation methods, the factors that determine landscape preferences, the steps in appreciation, and so forth.

There is no consensus on what the phenomenon of 'landscape' truly is (Jones 1991; Brabyn 2009), how people physiologically and mentally experience it, which human attributes affect the perception of it, and why it is apprehended the way it is (Aoki 2007). Some researchers agree that people from various distinctive cultures prefer natural environments to built or otherwise human-influenced ones (e.g., Kaplan and Kaplan 1989; Yang and Kaplan 1990; Ulrich 1993; van den Berg et al. 2003). They explain these preferences in terms of 'attention restoration theory': natural environments offer support for the recovery of attention, which is a very limited resource that is easily exhausted in daily life, including work. Several studies conclude that the similarities in the visual evaluation of landscapes surpass the differences across cultures as well as smaller groups (Purcell et al. 1994; Herzog et al. 2003; Staats and Hartig 2004). Some authors interpret these similarities as supporting an evolutionary theory of human landscape preferences (Appleton 1975; Orians 1986; Kaplan 2001). However, other studies identify individual and intergroup distinctions in environmental preferences within an evolutionary framework, in addition to the similarities (Hull and Reveli 1989; Dramstad et al. 2006). Bourassa (1991) suggests that the difficulties in understanding landscape derive from human evolution and are affected by both ontogenesis and phylogenesis. He proposes a need for three steps of clarification that consider 'biological and cultural constraints and personal idiosyncrasies' (Bourassa, 1991, p. 110). Lothian (1999) emphasizes that many contemporary theories of landscape quality have adopted Kant's subjectivist view of aesthetics, which identifies beauty as 'in the eye of the beholder' rather than in the actual object. Backhaus (2011) concludes that there is no such thing as an absolute perspective on landscapes; people can perceive the same landscape in different ways.

Two kinds of respondent attributes could influence landscape preferences. The first involves the identities of a human group (e.g., nationality, ethnicity, living environment, gender, and age) (Tips and Savasdisara 1986; Takayama et al. 2012). The second includes individual characteristics (e.g., social status, personal history, educational level, and professional interests, hobbies) (Aoki 2007). Kaltenborn and Bjerke (2002) argue that both cultural and genetic factors may contribute to evaluative responses to environmental types. According to Appleton (1975), original landscape appreciation derives from respondents' on-site experiences; it can evolve with physiological, and even sociological, age (Aoki and Kitamura 2001). Thus, aesthetic perception is a complex process that combines a person's sensory abilities, which are both inherent and acquired through training, education, and social development (Nikolaev 2005).

A natural environment that is native, or the most familiar, to respondents can determine landscape appreciation as well. According to Leo Gumilyov (1993), the famous Russian ethnologist and founder of ethnogeny theory, there is an indissoluble union between ethnos and its surrounding landscape; thus, this relationship can exert influence upon people's perceptions of the world. Therefore, when studying human landscape preferences, it is important to compare them with landscapes that respondents consider familiar and unfamiliar (exotic).

The 'outside views' of the representatives of other cultures allow us to see the unusual in the usual, take a fresh look at familiar landscapes, descry their originality and beauty, and experience new aesthetic features. A good example is the influence of Russian literature on forest landscape appreciation in Japan. After Japan was opened to foreigners during the Meiji Era (in the late 19th century), the Japanese writers Doppo Kunikida and Roka Tokutomi became interested in Russian literature. Poetic descriptions of forests by Russian writers such as Ivan Turgenev and Leo Tolstoy stimulated these Japanese men of letters to recognize the beauty of deciduous forests as well, to praise them in their own works (Kunikida 1901), and to use deciduous trees (zokibayashi in Japanese) in their formalized gardens. In earlier times, people in Japan did not consider such trees aesthetically valuable and only used them as firewood. In this sense, the Russian appreciation of forests facilitated the first step toward the widespread preservation of forest landscapes in Japan (Okajima et al. 2010).

With regard to the authors mentioned above, in our conception of natural landscape appreciation, we assume 
that people belonging to different cultures differ in their landscape preferences as a result of a number of ethnocultural features, as well as historical, social, and environmental factors. It is very important to reveal and consider these differences. The purpose of this study is to compare human landscape preferences, visual and emotional perception, and the aesthetic evaluation of natural landscapes by Japanese and Russians. Both Japan and Russia have deeply rooted cultural traditions regarding natural landscape appreciation. Our countries share a common border and also have areas with similar natural environments; they differ, however, in cultural, social, historical, and economic aspects. We believe that such a cross-cultural analysis is not only interesting from a theoretical perspective but also very useful in practical and humane aspects, as it should promote a better understanding for solving many intercultural issues, including international cooperation in landscape protection, management, and planning.

\section{Methods}

\section{Visualization of landscapes}

All of the senses are involved in the aesthetic perception of landscape. However, we receive almost $90 \%$ of aesthetic information through contemplation (Nikolaev 2005). Thus, in contrast to the geoscientific analysis of landscape, which investigates its substantive properties, aesthetic perception mainly deals with landscape appearance - views or scenery that are contemplated by a perceptive and communicative observer. The aesthetic evaluation of landscape is primarily one of visual assessment. Therefore, a very important aspect of our research is visual landscape presentation. In the early stages of landscape studies in Russia, Japan, and other countries, the on-site approach prevailed, wherein respondents visited the survey areas and evaluated them directly (Sevenant and Antrop 2009). However, this approach limited the number of respondents, visits, and sites (Aoki 1999). Thus, we have chosen another approach that focuses on color photos.

First, we created a digital photo database of natural landscapes both similar and unique for Russia and Japan using the principles for taking pictures described by Petrova et al. (2008a). Almost 900 pictures were taken in different geographical, climatic, and landscape zones of both countries. Our goal was to show the greatest variety of Russian and Japanese landscapes. All the pictures are documentary images of landscapes taken with equally sharp focus from front to back under normal lighting at eye level using wide-angle lenses with a focal distance of 28 to $35 \mathrm{~mm}$ (equivalent to a $35 \mathrm{~mm}$ film camera), which corresponds to the angular span of the human eye. We did not apply any of the special effects used in artistic photography, such as concentrating on certain foreground objects with a blurred background, beautiful sunsets and sunrises, spectacular beams of light that illuminate specific objects, spectacular mists, 'silky' water, and increased contrast that focuses on particular elements. Nor did we use any editing programs that divert attention from the perception of landscapes as a whole and emphasize particular objects.

\section{Selection of photo images}

For the survey procedure, we selected 70 photographs from the database. They represented in equal numbers the main types of Russian and Japanese landscapes in seven categories: forests, treeless plains (including tundras, wetlands, and steppes), mountains, river valleys, waterfalls, lakes, and seacoasts. Based on the opinion of six Russian and six Japanese professionals, we defined the number of pictures and the range of categories, which together offer an idea of the diversity of natural landscapes in both countries. We selected the specific images for each category, which included five pictures of Russia and five of Japan, using soft preferential voting by the same experts (Aoki and Petrova 2010). When choosing this selection of 70 images, we were limited by the actual duration of respondent interviews at university centers (two academic hours). In our experience, respondents generally require more time to properly evaluate a larger number of photographs.

During the interviews, each respondent received the same set of 70 photos, which were printed in postcard format $(13 \mathrm{~cm} \times 18 \mathrm{~cm})$. The order of the photos was random but the same for all participants. To avoid influencing respondents' opinions, we did not specify geographical characteristics such as landscape category, object, or survey area.

\section{Respondents and survey procedures}

Aiming to discover possible landscape preferences based on ethno-cultural and regional differences, we invited respondents with similar social and demographic characteristics (age, education, social status, etc.) from different regions of Japan and Russia. We conducted surveys at universities in Russia (Moscow State University in Central Russia, Irkutsk State University in East Siberia, and Kamchatka State University in Far Eastern Russia) and Japan (Hokkaido University, Chiba University, and Miyazaki University). When selecting these university centers, we were guided by the same principles: the metropolitan areas of both countries and two outlying regions, which differ most strongly in their natural environments, were represented. Students, young teachers, and researchers, mainly in geosciences as well as the humanities, ranging from 17 to 30 years of age participated in the survey. There was a roughly equal number of men and women. We interviewed 248 respondents (about 40 to 50 respondents from each region); this group size is 
generally considered sufficient for polls within homogenous groups (Ermolaev 2003).

We asked each respondent

- to fill out a form requesting personal data (age, gender, education, etc.);

- to group all 70 landscape images according to personal perceptions of their visual similarities and name each group;

- to rate the attractiveness and exoticism of each landscape image; and

- to characterize the natural landscapes of Russia and Japan, respectively, using just three words.

The groupings of landscape images allowed us to discover which components were more important for respondents in their visual and emotional landscape classifications and how they interpreted the landscapes in the photos.

To evaluate the attractiveness of landscapes, we used a five-point scale where ' 5 ' indicated the most attractive landscape while ' 1 ' denoted an extremely unattractive landscape. A simpler three-point scale was chosen to assess the exoticism of landscapes, with exotic landscapes marked as ' +1 ' and familiar ones ' -1 .' When respondents could not decide between these categories, they chose ' 0 .' Comparing the attractiveness evaluation with the 'exotic versus familiar' assessment of the same landscapes, we tried to discover whether 'exotic' or 'familiar' landscapes were more preferable to the respondents and whether these attributes might influence the assessment of landscape attractiveness.

In the Japanese study areas, respondents were interviewed in Japanese; in Russia they were interviewed in Russian; therefore, there were no linguistic difficulties.

\section{Statistical analysis}

Data obtained from the interviews were analyzed using elementary and multivariate statistical methods.

We summarized the results of the photo groupings by comparing the seven landscape classifications, thus accumulating the 'collective opinion' of respondents from every region and in all study areas of Russia and Japan as a whole. For this, we calculated how often each image co-occurred with any of the other 69 images within the same landscape group as reported by each respondent. Then, we processed the resulting matrices of co-occurrence frequencies using modified factor analysis in the Statistical Package for the Social Sciences (SPSS 16.00 FULL). This method is based on hierarchical agglomerative clustering in which two images with the highest correlation in a multidimensional (in this case, 70-dimensional) space are merged into a cluster. These clusters consequentially form larger groups with lower correlations. It is important to note that a number of agglomeration steps and a number of clusters were not defined a priori but automatically produced by the algorithm. Thus, our initial set of landscape categories, which was unknown to the respondents, could not influence their classifications.

To reveal the similarities and differences in the assessment of landscape attractiveness and landscape exoticism between different groups of Russian and Japanese respondents, we calculated their mean scores for each landscape image. We used Student's $t$-test to assess the statistical significance of the differences between the estimates of landscape attractiveness by the Russian and Japanese respondents. When the Student's $t$-test values exceeded 2.58, the differences between their estimates were considered significant (error probability: $p<0.01$ ); for values less than $1.96(p>0.05)$, they were taken as insignificant, while for values of $1.96<t<2.58$ they were taken as undefined.

We also calculated the words Russian and Japanese respondents used most often to characterize the natural landscapes of both countries.

Statistical analysis allowed us to reveal some of the common features and main points of difference between Russian and Japanese respondents, as well as between groups of Russian respondents from different regions (Moscow, Irkutsk, and Kamchatka), in the visual and emotional evaluation of natural landscapes. Our analysis also discovered similarities between all groups of Japanese respondents in their assessments. Below, we discuss the main findings.

\section{Results and discussion}

\section{Visual and emotional grouping of landscapes}

Using hierarchical agglomerative clustering of the photographs, we obtained (1) six visual and emotional landscape classifications composed by each group of respondents and (2) a general visual and emotional landscape classification that comprises the 'collective' opinion of the Russian and Japanese respondents. In all cases, the revealed landscape groups generally corresponded to the set of landscape categories we used in our initial classification: forests, mountains, river valleys, waterfalls, lakes, and seacoasts. The only exceptions were 'treeless plains' that initially included images of tundras, wetlands, and steppes. The majority of respondents grouped them by the presence or absence of water in the picture and interpreted some images with water as 'swampy plains' or 'lowland rivers' and those without visible water as 'waterless plains.' This new set of landscapes identified by respondents was used as a legend for the resulting graphs showing the evaluation of attractiveness and exoticism (see pp. 7-8).

At a later step in the hierarchical agglomerative clustering of the photographs, forests, 'waterless plains,' and 'dry' mountains (without visible water in the photo) 
formed a larger group (super-group) of 'waterless' landscapes; 'swampy plains,' rivers, and waterfalls comprised a group of landscapes associated with river systems, while lakes and seacoasts formed a group of landscapes having large bodies of water (Table 1).

Thus, unlike 'geoscientific' landscape classifications where physical properties, genetic unity, and homogeneity in both zonal (bioclimatic) and azonal (geology and relief) conditions play the leading roles (Isachenko 1991) - the most important feature in the visual and emotional grouping of landscapes appears to be the presence/absence of water and the type of water basin (river, lake, sea). These results were common among all groups of Russian and Japanese respondents and support an idea regarding similarities in human perceptions and visual evaluations of natural scenes. Our findings are consistent with those of other studies focused on visual landscape characteristics that use water as the key landscape element (Yang and Brown 1992; Hull and Stewart 1995; Ode et al. 2008).

At the same time, we ascertained some differences between Russian and Japanese respondents in grouping landscapes. For example, the division of some landscapes into subgroups of mountains and plains was more important for Russian - especially Muscovite - respondents, who are the least familiar with mountains but most impressed by them. In this regard, our findings only partially correspond to those of other studies that also use topography as the main indicator of landscape character (Brush 1981; Arriaza et al. 2004; Nasar and Li 2004; Ode et al. 2008).

Only Russian respondents used topography as a key parameter when grouping lakes. Unlike the Japanese, the Russians did not yet recognize lakes as a separate group. They combined lowland lakes with lowland rivers (although both are very important natural features in Central Russia, sometimes it is difficult to distinguish them in the photos), characterized some big lakes as seacoasts, and merged mountain lakes with mountains. However, when grouping mountains, Russian respondents separated mountain lakes from 'dry mountains' and folded mountains from volcanoes. In comparison, Japanese respondents did not separate volcanic lakes from lakes in folded mountains; visual characteristics were more important to them: they divided lakes into three subgroups not by their geological origin or topography but by the visible size of the water surface in the picture. Moreover, Japanese (unlike the Russians) did not separate volcanoes from folded mountains when grouping mountain landscapes. They considered mountains as a single group. This is probably because many mountains in Japan are of volcanic origin, while in Russia folded mountains and active volcanoes are usually in different locales. It is also noteworthy that Japanese poets, who often praised the beauty of volcanoes, did not refer to them as 'volcanoes' but as simply 'mountains' (Meshcheryakov 2012).

Another interesting result is that our analysis of forest groupings revealed evident differences not only between Russian and Japanese respondents but also between different groups of Russian respondents. Thus, the Moscow respondents clearly divided forest landscapes into two subgroups of mountains and plain forests. Japanese respondents used, again, purely visual characteristics, separating distant views of forests from close-up views within forests and distinguishing winter forests (seasonal characteristics). However, the Irkutsk and Kamchatka respondents did not actually identify any subgroups of forest landscapes.

Ueda et al. (2012) obtained similar results when analyzing sketches of forest landscape images made by Russian and Japanese respondents. In the Japanese research sites, 'close-up view' was the predominant category followed by 'bird's-eye view.' However, the results for the Russian research sites showed important differences: the 'sideways view' in Moscow, the 'close-up view' in Moscow and Irkutsk, and the 'bird's-eye view' and 'distant view' in

Table 1 Landscape categories in the initial classification and landscape groups revealed by respondents

\begin{tabular}{|c|c|c|c|c|c|c|c|}
\hline \multirow{2}{*}{$\begin{array}{l}\text { Landscape groups (revealed by } \\
\text { respondents) }\end{array}$} & \multicolumn{7}{|c|}{ Landscape categories (in the initial classification) } \\
\hline & Forests & Waterfalls & Rivers & Treeless plains & Lakes & Seacoasts & Mountains \\
\hline \multicolumn{8}{|l|}{ Waterless landscapes } \\
\hline Forests & 10 & & & 1 & & & \\
\hline Waterless plains & & & & 4 & & & \\
\hline Waterless mountains & & & & 1 & & & 7 \\
\hline \multicolumn{8}{|c|}{ Landscapes associated with river systems } \\
\hline Waterfalls & & 10 & & & & & \\
\hline Swampy plains & & & 1 & 4 & & & \\
\hline Rivers & & & 8 & & & & \\
\hline \multicolumn{8}{|c|}{ Landscapes having large bodies of water } \\
\hline Seacoasts & & & & & 2 & 10 & \\
\hline Lakes & & & & & 9 & & 3 \\
\hline
\end{tabular}

The numbers indicate the number of photos belonging to this category or group of landscapes. 


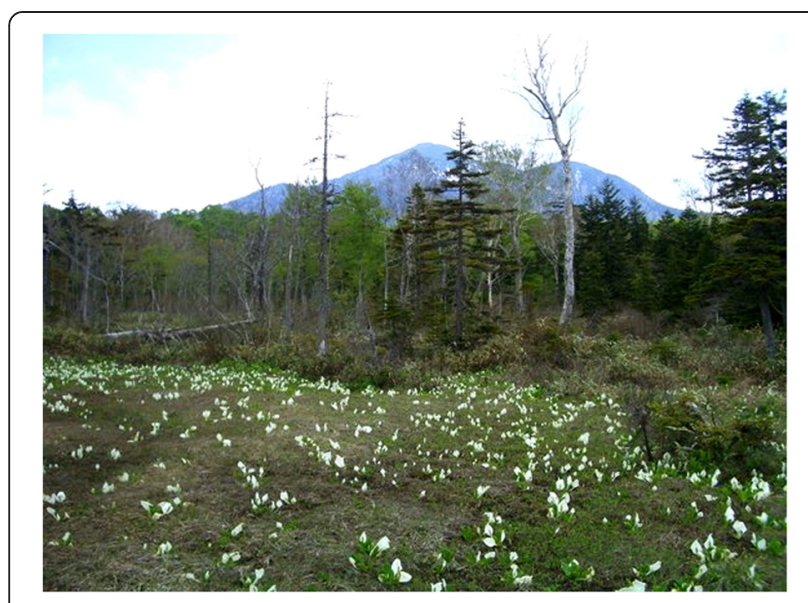

Figure 1 Landscape of Oze National Park in Japan.

Irkutsk and Kamchatka. We can explain these variations in terms of topography. The flat, vast terrains around Moscow do not provide 'distant' or 'bird's-eye' views of forests there, in contrast to the mountainous areas around Irkutsk, in Kamchatka, and in Japan. These differences between the survey regions explain why topography was the most important factor for the Moscow respondents' groupings of forest images, while the Japanese, Irkutsk, and Kamchatka respondents - who are more familiar with views from the outside of forests, which they usually see on mountain slopes in the background - did not consider this factor in their groupings.

In some cases, respondents interpreted the same landscape images differently. For example, the majority of Japanese respondents characterized the picture of Oze National Park in Japan (Figure 1) as a plain forest, Irkutsk and Kamchatka respondents saw it as a mountain forest, and the Moscow respondents considered it a swamp. We believe these interpretations also vary as a result of the differences in terrains between the study regions. For example, swampy landscapes are more familiar to the Moscow respondents than to the Japanese, who interpreted the stunted trees in the swamp as a forest; however, the Irkutsk and Kamchatka respondents focused on the mountains in the background rather than the swamp in the foreground.

\section{Evaluation of landscape attractiveness and exoticism}

During the interviews, we learned that the respondents considered attractive landscapes beautiful and comfortable, not only for long-term stays but also for permanent living. Exotic landscapes were considered unusual and foreign to the respondents. According to the respondents, even if such landscapes were unsightly, they would be interesting to visit at least once. Therefore, when assessing the attractiveness of familiar landscapes, respondents focused on both their aesthetic feelings and a sense of belonging - a sense of connection to the native landscape. However, in their assessments of the attractiveness of exotic landscapes, their cognitive interest in the unknown played an important role.

In general, there was a rather strong correlation between the estimates of landscape attractiveness by the Russian and Japanese respondents (correlation coefficient: $R=0.73$ ), which might indicate the existence of universal human concepts regarding landscape aesthetics. However, Russian respondents appeared more emotional while the Japanese tended to be more restrained in their assessments. As Table 2 shows, Russian respondents assessed almost all the landscape types significantly higher than the Japanese did. The only exceptions were treeless (both swampy and waterless) plains; all respondents assessed them lowly and almost identically. The most attractive types for both Russian and Japanese respondents were waterfalls, mountains, and lakes; the least attractive were

Table 2 Statistical significance of differences between estimates of landscapes attractiveness by Russian and Japanese respondents

\begin{tabular}{|c|c|c|c|c|c|c|c|}
\hline \multirow{2}{*}{$\begin{array}{l}\text { Group of } \\
\text { landscapes }\end{array}$} & \multicolumn{3}{|c|}{ Russian respondents } & \multicolumn{3}{|c|}{ Japanese respondents } & \multirow{2}{*}{$\begin{array}{c}\text { Student's } \\
\text { t-test }\end{array}$} \\
\hline & $n$ & $x$ & $s$ & $n$ & $x$ & $s$ & \\
\hline Waterfalls & 1,270 & 4.26 & 0.97 & 1,230 & 3.78 & 1.03 & 12 \\
\hline Mountains & 1,016 & 4.2 & 0.99 & 984 & 3.75 & 1.15 & 9.4 \\
\hline Lakes & 1,524 & 4.15 & 0.99 & 1,476 & 3.73 & 1.09 & 11.1 \\
\hline Seacoasts & 1,524 & 3.92 & 1.06 & 1,476 & 3.34 & 1.14 & 14.4 \\
\hline Rivers & 1,016 & 3.86 & 1.05 & 984 & 3.69 & 1.03 & 3.7 \\
\hline Forests & 1,397 & 3.72 & 1.08 & 1,353 & 3.32 & 1.16 & 9.4 \\
\hline Swampy plains & 635 & 3.56 & 1.11 & 615 & 3.4 & 1.16 & 2.5 \\
\hline Waterless plains & 508 & 3.08 & 1.21 & 492 & 3.07 & 1.18 & 0.1 \\
\hline All & 8,890 & 3.93 & 1.08 & 8,610 & 3.54 & 1.13 & 23.3 \\
\hline
\end{tabular}

$n$, number of estimates; $x$, average score; $s$, standard deviation.

Significant values $(t>2.58 ; p<0.01)$ are marked in bold, undefined values $(1.96<t<2.58 ; 0.01>p<0.05)$ in bold italics, and insignificant values $(t<1.96 ; p>0.05)$ in italics; $p$, error probability. 


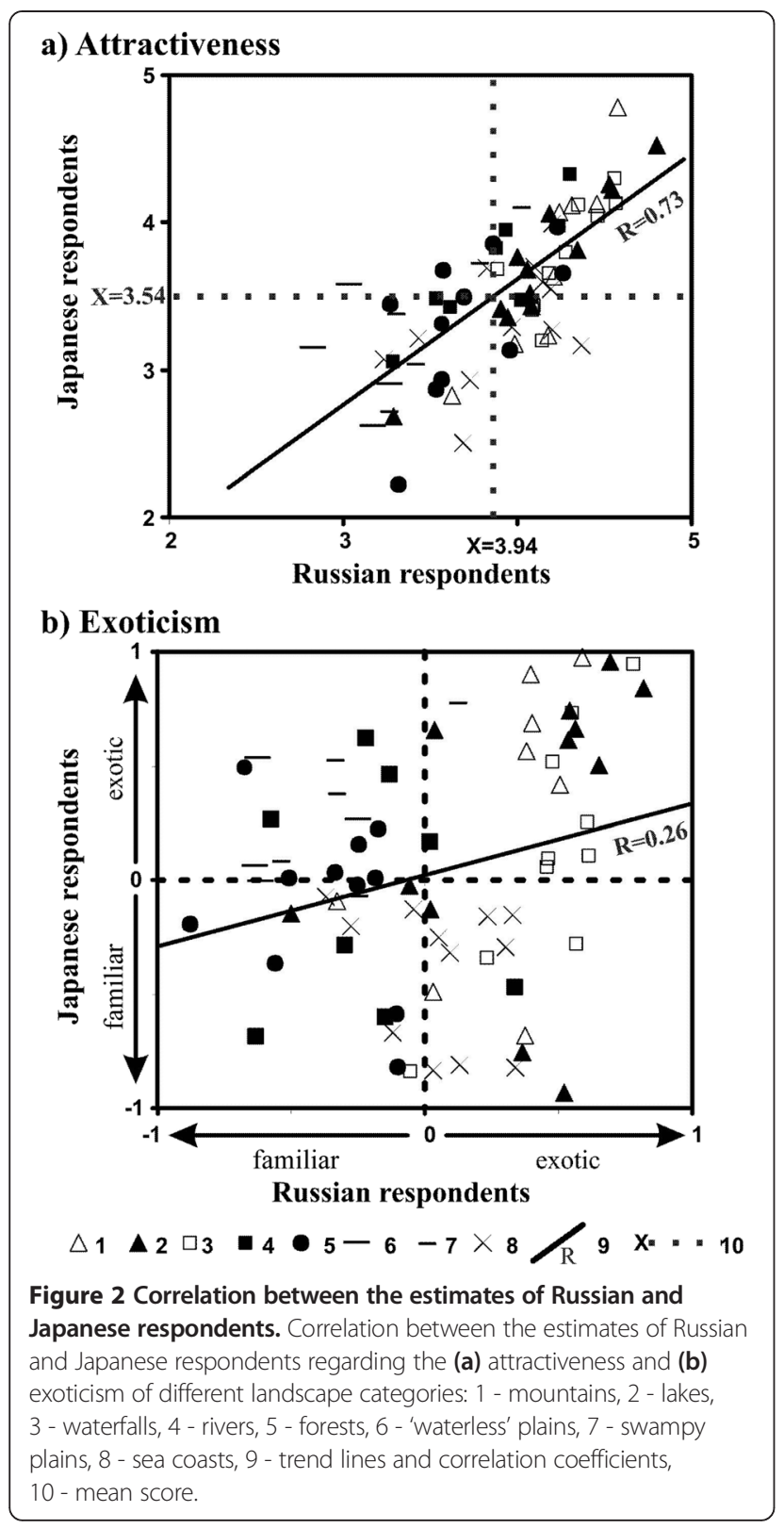

waterless plains (Figure 2a, Tables 3 and 4). The special importance of water and topography in the human experience of landscape is also evident in earlier research on preference (e.g., Brush 1981; Wherrett 2000; Arriaza et al. 2004; Nasar and Li 2004). However, the Russians and Japanese evaluated some other types of landscapes, including waterscapes, differently. Such differences apply to seacoasts, rivers, forests, and swampy plains, which tended to be ranked intermediately in their assessments. Russian respondents assessed the attractiveness of both seacoasts and rivers significantly higher than forests and swampy plains and substantially higher than waterless plains. For Japanese respondents, rivers were almost as attractive as waterfalls, mountains, and lakes, but seacoasts were noticeably less attractive.

There was practically no correlation between Russian and Japanese respondents in evaluating exotic/familiar landscapes $(R=0.26)$. The majority of Russian respondents considered mountain landscapes (including mountain lakes and waterfalls) and seacoasts as the most exotic, while forests, rivers, and treeless plains were the most familiar. For Japanese respondents, seacoasts were familiar and treeless plains exotic; all other landscapes varied considerably in their assessments (Figure 2b).

All groups of Japanese respondents were virtually identical in their assessments of the attractiveness and exoticism of landscapes (correlation coefficients between their scores: $R=0.90$ to 0.96 ). Among the Russian respondents, in comparison, participants from different regions evaluated them differently. This is probably because Japan is a more culturally homogeneous nation (Meshcheryakov 2010). However, the natural environment can also play a role here: the regions of Russia in which we performed our investigations differ significantly in their natural characteristics; meanwhile the Japanese regions vary mainly in their climatic conditions but are geomorphologically similar.

To discuss the ethno-cultural aspects of the perception and aesthetic evaluation of landscapes, it is appropriate to compare the survey data from Kamchatka and

Table 3 Statistical significance of differences (Student's $t$-test) between the attractiveness estimates of different landscape types by Russian respondents

\begin{tabular}{|c|c|c|c|c|c|c|c|c|c|}
\hline$x$ & Group of landscapes & Waterfalls & Mountains & Lakes & Seacoasts & Rivers & Forests & Swampy plains & Waterless plains \\
\hline 4.26 & Waterfalls & 0 & 1.5 & 2.9 & 8.8 & 9.4 & 13.5 & 14.1 & 22.1 \\
\hline 4.2 & Mountains & & 0 & 1.2 & 6.7 & 8.5 & 11.1 & 12.2 & 19.9 \\
\hline 4.15 & Lakes & & & 0 & 7.7 & 7.1 & 11.2 & 12.2 & 20.4 \\
\hline 3.92 & Seacoasts & & & & 0 & 1.4 & 5 & 7.1 & 15.3 \\
\hline 3.86 & Rivers & & & & & 0 & 3.2 & 5.5 & 13.4 \\
\hline 3.72 & Forests & & & & & & 0 & 3.1 & 11.3 \\
\hline 3.56 & Swampy plains & & & & & & & 0 & 7.2 \\
\hline 3.08 & Waterless plains & & & & & & & & 0 \\
\hline
\end{tabular}

The legend for Table 2 applies here as well. 
Table 4 Statistical significance of differences (Student's t-test) between the attractiveness estimates of different landscape types by Japanese respondents

\begin{tabular}{|c|c|c|c|c|c|c|c|c|c|}
\hline$x$ & Group of landscapes & Waterfalls & Mountains & Lakes & Rivers & Swampy plains & Seacoasts & Forests & Waterless plains \\
\hline 3.78 & Waterfalls & 0 & 0.6 & 1.2 & 2 & 7.2 & 10.4 & 10.6 & 12.4 \\
\hline 3.75 & Mountains & & 0 & 0.4 & 1.5 & 5.9 & 8.7 & 8.9 & 10.6 \\
\hline 3.73 & Lakes & & & 0 & 0.9 & 6.2 & 9.8 & 9.7 & 11.4 \\
\hline 3.69 & Rivers & & & & 0 & 5.2 & 7.7 & 8 & 10.4 \\
\hline 3.4 & Swampy plains & & & & & 0 & 1.1 & 1.4 & 4.7 \\
\hline 3.34 & Seacoasts & & & & & & 0 & 0.5 & 4.5 \\
\hline 3.32 & Forests & & & & & & & 0 & 4.1 \\
\hline 3.07 & Waterless plains & & & & & & & & 0 \\
\hline
\end{tabular}

The legend for Table 2 applies here as well.

Hokkaido. Hokkaido is Japan's northernmost island and the closest to Kamchatka in terms of natural conditions. Our analysis revealed that the Kamchatka respondents (along with other Russians) were slightly more attracted to seacoasts (Figure 3a). In all other respects, Kamchatka and Hokkaido respondents evaluated the attractiveness of different landscape types similarly $(R=0.72)$ and about the same way as Russian and Japanese respondents as a whole $(R=0.73)$.

A more complex pattern can be observed when comparing estimates of landscape exoticism (Figure 3b). In general, the correlation coefficient between the estimates of Kamchatka and Hokkaido respondents was low and only slightly higher $(R=0.37)$ than that between Russian and Japanese respondents $(R=0.26)$. This means that the residents of Kamchatka and Hokkaido, despite living in similar environments, did not always evaluate familiar/ exotic landscapes similarly. In some assessments, they were closer to the representatives of their culture, living under fundamentally different natural conditions. Crosscultural differences were most evident in the evaluations of treeless plains, forests, and rivers. Hokkaido respondents (like other Japanese) considered treeless plains exotic, but Kamchatka residents considered them familiar (like other Russians). All Russian respondents, including respondents from Kamchatka, considered forests and rivers familiar, while Japanese respondents, including respondents from Hokkaido, rated them very differently from the most familiar to the most exotic.

At the same time, Kamchatka respondents' evaluations of some landscapes were virtually identical to those of Japanese respondents (including Hokkaido) and very different from those of Russian respondents from other regions. This applies to seacoasts and mountains, which are both the most remarkable and most similar landscape types in Kamchatka and Japan. Seacoasts were familiar to residents of Japan and Kamchatka but exotic to other Russians. The exoticism of mountain landscapes varied among all groups, but the ratio of 'exotic' to 'familiar' mountains was the same for Kamchatka, Hokkaido,

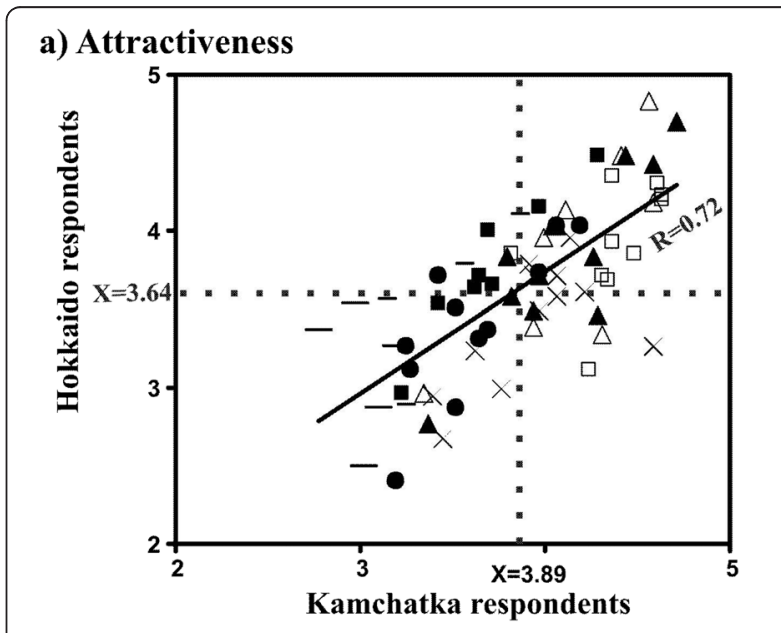

b) Exoticism

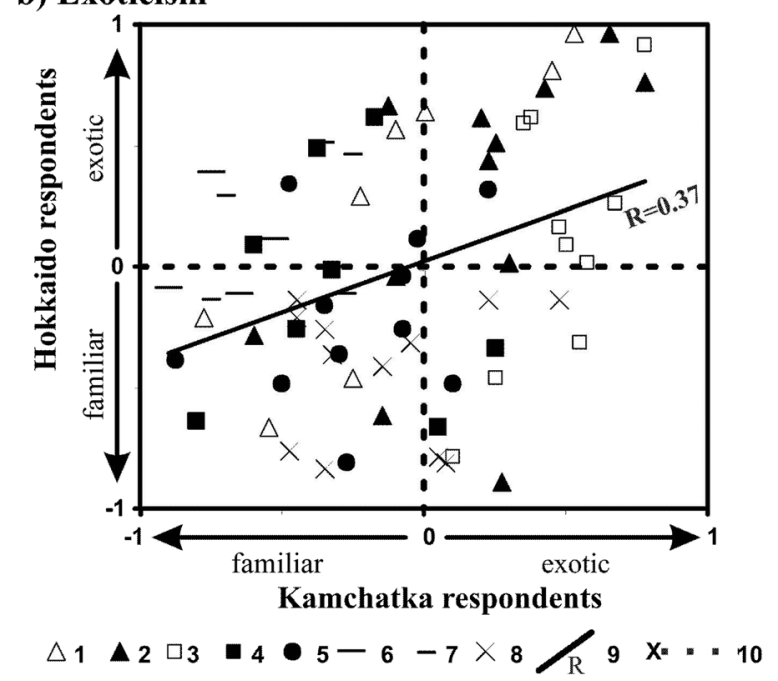

Figure 3 Correlation between the estimates of Kamchatka and Hokkaido respondents. Correlation between the estimates of Kamchatka and Hokkaido respondents regarding the (a) attractiveness and (b) exoticism of landscapes. Explanations in Figure 2. 
and Japan and was equal to two; for Irkutsk it was five, and for Moscow respondents it was 14.

Russian respondents were apparently more attracted to the most exotic landscapes. The correlation coefficient between their estimates of attractiveness and exoticism was 0.80 ; it was lower $(R=0.52)$ only for the Moscow respondents. For all Russian respondents, mountain lakes, mountains, and waterfalls were the most attractive and simultaneously the most exotic, followed by seacoasts and rivers, at that, rocky coasts were more attractive than sandy beaches, and mountain streams were more attractive than lowland rivers. The majority of Russian respondents considered forests and treeless plains the most familiar and least attractive. However, forests were more attractive than treeless plains, especially for residents of Irkutsk and Kamchatka.

Every group of Russian respondents also appreciated a small group of familiar but nevertheless attractive natural sites. Thus, for most Russians, Lake Baikal (Figure 4) was not only one of the most beautiful but also easily recognizable natural symbols of Russia; for the Irkutsk respondents, it was also a closely located natural object. Similarly, for the Moscow respondents, Moskva River (Figure 5), as well as the forests and lakes of Central Russia, were familiar and attractive sites. Respondents from Petropavlovsk-Kamchatsky appreciated the Koryak, Avachinsky, and Karymsky volcanoes, as well as the 'Three Brothers' cliffs, which are the most beautiful natural objects close to the city. Thus, not only exotic landscapes but also the symbols of native nature were attractive for Russian respondents. Similarly, only one among many volcanoes was familiar and attractive for the Japanese respondents: Mount Fuji (Figure 6).

For both Japanese and Russians, mountains, mountain lakes, and waterfalls were not only the most attractive but also exotic. However, in contrast to the Russian respondents, there was no correlation between the evaluations of exotic and attractive landscapes in any of the Japanese

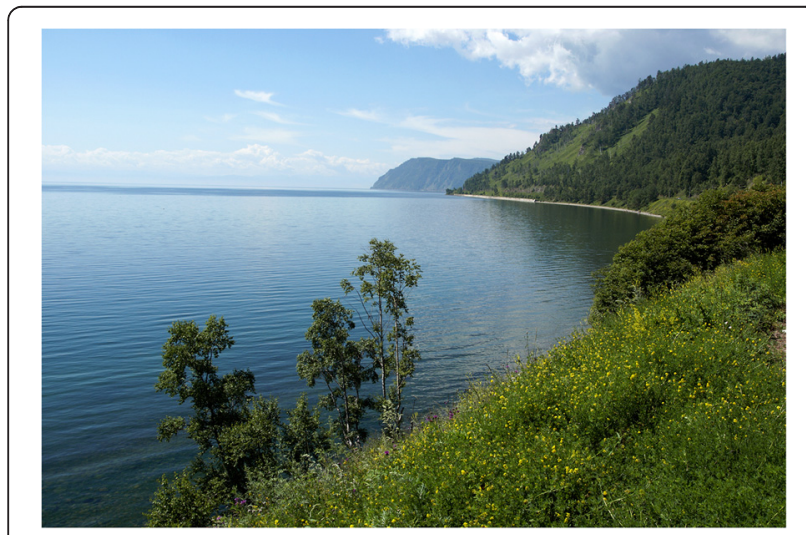

Figure 4 The most attractive of familiar landscapes according to Russian respondents: Lake Baikal.

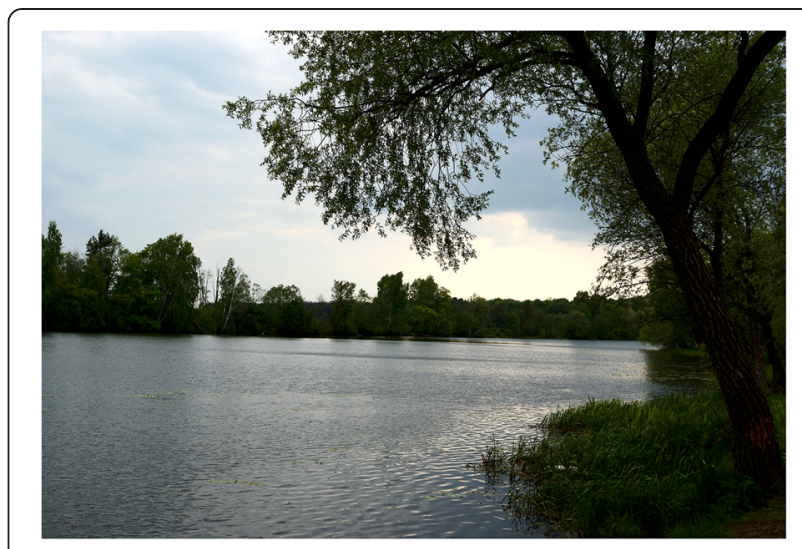

Figure 5 The most attractive of familiar landscapes according to Moscow respondents: Moskva River.

groups $(R=0.26$ to 0.35$)$. Japanese cultural traditions - a settled way of life and traditional appreciation of Japan's natural environment as the most beautiful and comfortable for living, unlike that of foreign countries (Meshcheryakov 2010) - might play a role here. For example, treeless plains were among of the most exotic but unattractive landscape types in Japan. The attractiveness and exoticism of forests and rivers varied considerably in their estimates (Figure 2).

Seacoasts were familiar for both Japanese and Kamchatka respondents (Figure 3b). However, if the coasts were very attractive for Kamchatka residents, they were less so for the Japanese. This is probably due to traditional perceptions as well. Despite the fact that Japan is surrounded by the sea, for most of its history, the state has positioned itself as not a marine but rather agricultural and mainland nation. In traditional Japanese culture, the sea was more often represented in terms of 'negative elements': Japanese writers and poets did not praise it in their works, educated people never made sea voyages, and fishermen were perceived as rude,

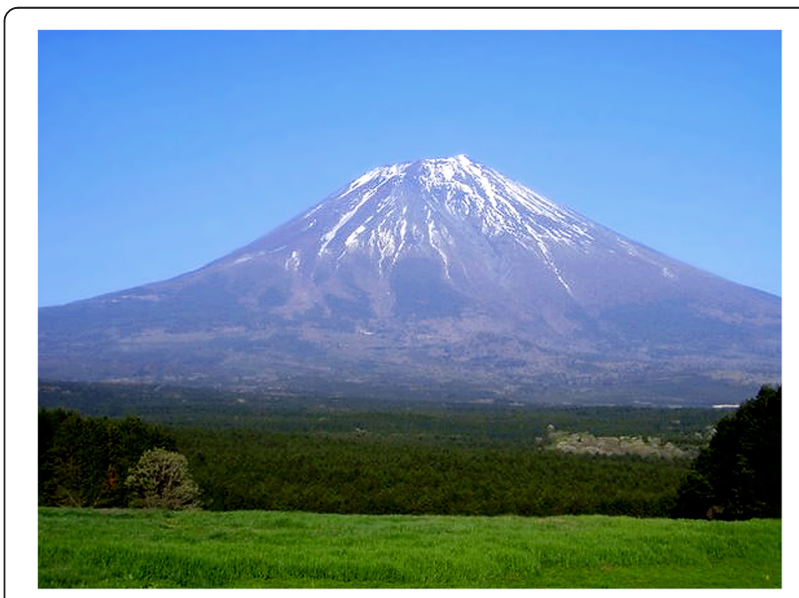

Figure 6 The most attractive of familiar landscapes according to Japanese respondents: Mount Fuji. 
uncouth people with a significantly lower social status than that of peasants (Meshcheryakov 2012).

Accordingly, we can assume that differences in the assessment of attractiveness and exoticism are associated with both cultural differences (traditional perceptions) and the features of the natural environments the respondents live in or have had experiences with. Thus, all Russian respondents regarded as familiar landscapes relevant to not only their own region but also their historical homeland - that is, Central European Russia, the center of Russian civilization.

\section{Prevailing images and the real diversity of landscapes in} Russia and Japan

Russian respondents characterized nature in Japan in terms of 'mountain/volcano', 'island/sea/ocean/coast', 'beauty', and 'sakura' (Japanese cherry tree). This is close to the opinions of Japanese people ('mountains', 'sea', 'rivers', and 'four seasons'). Even the first Russian travelers to the country in the 19th century, such as the writer Ivan Goncharov, admired the exotic and diverse beauty of Japan's natural features. According to Goncharov, 'All is so harmonious, so picturesque, and so different from reality here' (as cited in Petrova et al. 2010, p. 195). The Japanese respondents, however, imagined nature in Russia as a set of quite unattractive landscapes ('coniferous forest/taiga,' 'boundless plains', 'tundras') and additionally characterized it using words such as 'snow' and 'cold.' This image only partly coincides with that of the Russian respondents: 'forest/taiga,' 'space/plain', 'river,' and 'mountain' (the last one was added by the Irkutsk and Kamchatka respondents).

Neither image reflects the real natural diversity of both countries (Petrova et al. 2008b). This conclusion is also confirmed by the fact that the Russian respondents, who had never been to Japan, perceived many Japanese landscapes as 'familiar' Russian landscapes (Figure 7a). Moreover, many landscapes in Russia were no less exotic to them than the 'typical' landscapes of Japan. Similarly, the Japanese respondents, who had never been to Russia, often did not distinguish between Russian and Japanese landscapes (Figure 7b). It is also paradoxical that many mountain landscapes, which are characteristic components of nature in both Japan and Russia according to the respondents, were evaluated as not only the most attractive but also the most exotic (Figure 2b). Moreover, a set of six photos of the most attractive exotic landscapes was identical for the Russian and Japanese respondents. All of these pictures were taken in Russia: the Altai, the Caucasus, the Khibiny Mountains (north of European Russia), and the unique mountain plateau Putorana in Central Siberia.

Thus, the prevailing views regarding the 'typical' natural landscapes in Russia and Japan, and the fundamental differences between them, do not adequately reflect the diverse natural features of both countries. Such views could be

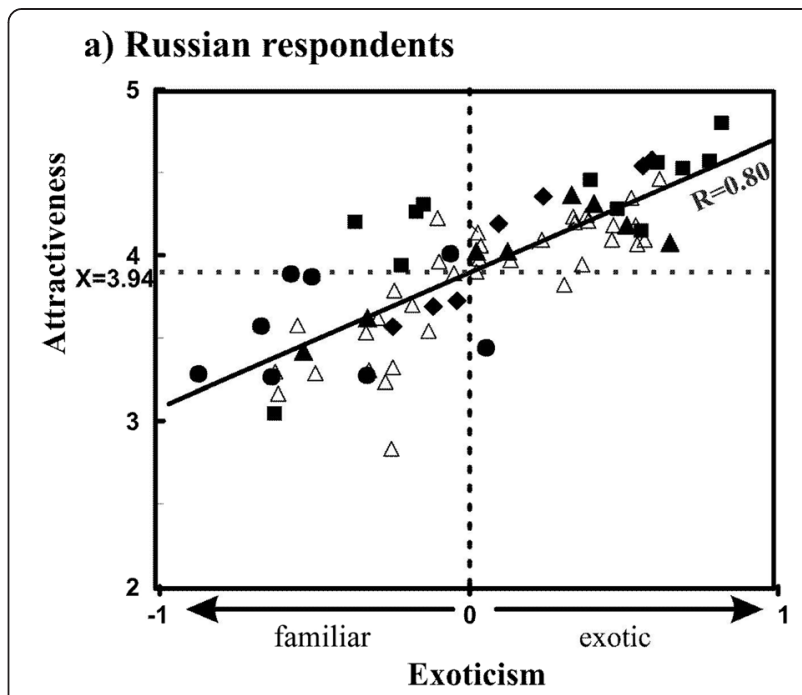

b) Japanese respondents

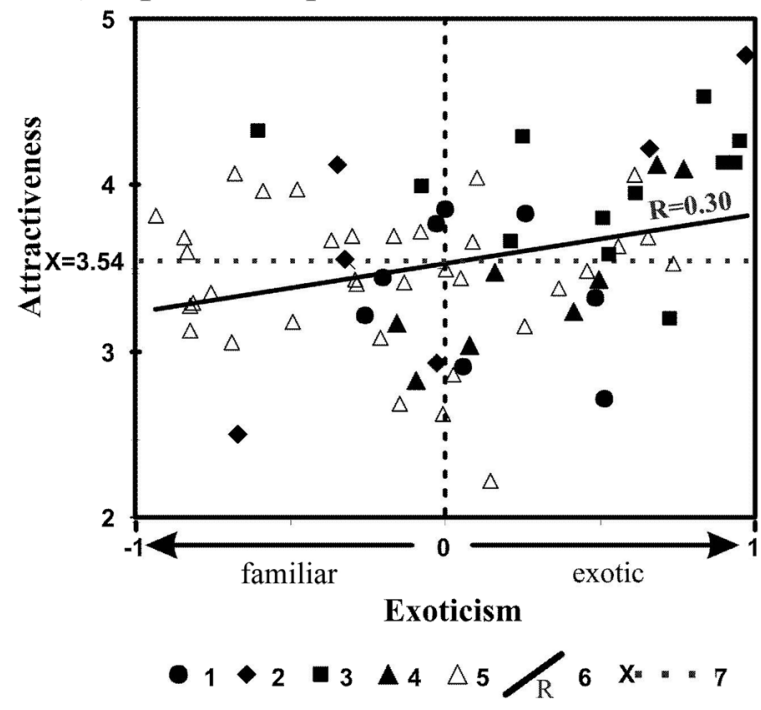

Figure 7 Correlation between the evaluation of attractiveness and exoticism according to Russian and Japanese respondents. Correlation between the evaluation of attractiveness and exoticism according to (a) Russian and (b) Japanese respondents of different regions: 1 - plains of European Russia, 2 - Khibiny and Caucasus mountains, 3 - Central and East Siberia, 4 - Kamchatka, 5 - Japan, 6 - trend lines and correlation coefficients, 7 - mean score.

attributable to the fact that mass media and literature tend to pay special attention to the flat landscapes of the Central European part of Russia and the limited number of famous mountainous landscapes in central and southern Japan; meanwhile, other landscapes in both countries remain practically unknown to the larger population. We hope our study will help to remedy this gap.

\section{Conclusions}

Previous investigations of landscape preferences tended to explain the matter through theoretical concepts that 
focused on either individual and cultural differences or evolutionary processes. Our analysis has shown that these factors interact in a much more complicated way. It allowed us to reveal some common features of and main differences in the perception and visual evaluation of natural landscapes between Russian and Japanese respondents, as well as between Russian respondents from different regions (Moscow, Irkutsk, and Kamchatka).

The survey process involved grouping landscapes according to respondents' personal preferences as well as rating the attractiveness and exoticism of landscapes. The results can be summarized as follows.

The most important feature for grouping landscapes appeared to be the presence or absence of water as well as the type of water basin. Topography was also very important for the Russians (especially the Muscovite respondents), while both visual and seasonal characteristics were more significant for the Japanese.

Japanese respondents tended to be more restrained and the Russians more emotional in their assessments of landscape attractiveness; however, almost all assessed waterfalls, mountains, and lakes as the most attractive and waterless plains as the least. These common features might confirm the existence of universal human concepts regarding landscape aesthetics.

On the other hand, Russian and Japanese respondents evaluated some other types of landscapes differently (e.g., seacoasts, rivers, forests, swampy plains).

While Russian respondents considered the most exotic landscapes the most attractive, there was no such tendency for the Japanese. Respondents from both countries equally regarded the most famous symbols of native nature as very attractive.

It is interesting that all Japanese respondents assessed the attractiveness and exoticism of landscapes almost identically, while Russian respondents from different regions expressed different opinions. These results support the hypothesis that landscape preferences are influenced by not only the cultural factors determined by a country's traditions but also the features of familiar natural environments.

We hope our findings will not only be useful in the theoretical aspect but will also promote a better understanding between both cultures regarding issues of landscape protection, management, and planning. First of all, this refers to natural objects that can be used for recreational purposes because they are aesthetically valuable or exotic. We also hope to continue our research, engaging with more respondents of different ages and from different regions.

\section{Competing interests}

The authors have no competing interests to declare.

\section{Authors' contributions}

YA proposed the topic and conceived and designed the study. HM and NT helped develop the methodology for interviewing the respondents. YM, EP YA, and HM created the photo database. EP, SE, KF, HU, and AP conducted the experimental study. YM analyzed and helped interpret the data. HM and AP collaborated with the corresponding author in constructing the manuscript. All authors read and approved the final manuscript.

\section{Authors' information}

EP holds a PhD in geography. She is a Senior Researcher with the Faculty of Geography, Lomonosov Moscow State University. She is the Russian side leader of this research project. She is associated with Russian Geographical Society, European Geosciences Union, and Japan Geosciences Union.

YM holds a PhD in geology and mineralogy. He is a Senior Researcher with the Vernadsky State Geological Museum of the Russian Academy of Sciences. His current research interests include aesthetic evaluation and appreciation of natural landscapes. He is associated with Russian Geographical Society. YA holds a PhD in engineering. Until 2009, he was a special senior researcher in the Social and Environmental Systems Division of the National Institute for Environmental Studies in Tsukuba, Japan. He was the initiator and Japanese-side leader of this research project until 2008. He is now retired. In 2006, he received a prize from the head of the Academic Committee at the Center of Environmental Information Science. He is affiliated with the National Parks Association, Tourism Research Association of Japan, International Haiku Association, Japan IFLA, and others.

HM holds a PhD in agriculture. He is a lecturer at Hokkaido University and has been the Japanese-side leader of this project since 2009. His research interest is the conservation of neighborhood nature and its sustainable recreational use, especially for coastal areas.

SE was previously a student at Hokkaido University and conducted the questionnaire and analysis mainly in 2009. He now works as an officer in Nasushiobara.

KF holds a PhD and is an associate professor at Chiba University. His research interest is the conservation of nature and its sustainable recreational use, especially in national parks.

AP holds a PhD in history. She is a researcher in the Institute for Oriental Studies at the Russian Academy of Sciences. Her research interests include the history of the Orient and Orientalism. She is affiliated with the European Geosciences Union and the Japan Geosciences Union.

NT holds a PhD in agriculture. He is currently a researcher at the Forestry and Forest Products Research Institute in Tsukuba, Japan. He contributed to the research design and joint investigation of this project. His research interest is the effect of forest environments on psychological restorativeness. $\mathrm{HU}$ holds a PhD and is a lecturer at Sapporo City University. His research interest is the establishment of environmental design methods that involve the place attachments of citizens.

\section{Acknowledgements}

The Japan Society for the Promotion of Science and Russian Foundation for Basic Research supported this work under grant number 08-05-91204. We express our gratitude to the following for their help in organizing interviews with respondents: Olga Leontyeva, Yaroslav Muravyev, Alexey Naumov, Naokata Okajima, Lidiya Roman, Nikolay Seliverstov, Yury Semenov, and Alexander Cherkashin. We give special thanks to Richard B. Cathcart for his kind help in improving our English text.

\section{Author details}

${ }^{1}$ Faculty of Geography, Lomonosov Moscow State University, GSP-1, Leninskie Gory, Moscow 119991, Russia. ${ }^{2}$ Vernadsky State Geological Museum of the Russian Academy of Sciences, Mokhovaya 11, Bldg.11, Moscow 125009, Russia. ${ }^{3}$ Research Faculty of Agriculture, Hokkaido University, Kita 9, Nishi 9, Kita-ku, Sapporo 060-8589, Japan. ${ }^{4}$ Graduate School of Horticulture, Chiba University, 648, Matsudo, Matsudo-shi, Chiba 271-8510, Japan. ${ }^{5}$ Institute for Oriental Studies of the Russian Academy of Sciences, Rozhdestvenka 12, Moscow 107031, Russia. ${ }^{6}$ Forestry and Forest Products Research Institute, 1 Matsunosato, Tsukuba, Ibaraki 305-8687, Japan. ${ }^{7}$ School of Design, Sapporo City University, Geijutsu-no-mori 1, Minami-ku, Sapporo 005-0864, Japan. ${ }^{8}$ Open University of Japan, Nishikamata 5-12-1, Ota-ku, Tokyo 144-0051, Japan.

Received: 3 July 2014 Accepted: 2 February 2015

Published online: 31 March 2015 


\section{References}

Aoki Y (1999) Trends in the study of the psychological evaluation of landscape. Landsc Res 24:85-94, doi:10.1080/01426399908706552

Aoki Y (2007) Recent trends of English paper on the psychological evaluation of landscape. J Environ Inf Sci 35(5):181-188

Aoki Y, Kitamura S (2001) Ontogenic and phylogenic evolution of the human appreciation of the landscape. Proceedings of the 38th IFLA world congress, Singapore, pp 114-122, 26-29 June 2001

Aoki Y, Petrova E (2010) Bilateral project of JSPS and RFBR on comparison of natural landscape appreciation between Russia and Japan: first stage. J Environ Inf Sci 38(5):105-110

Appleton J (1975) The experience of landscape. John Wiley \& Sons, London

Arriaza M, Canas-Ortega JF, Canas-Madueno JA, Ruiz-Aviles P (2004) Assessing the visual quality of rural landscapes. Landsc Urban Plan 69:115-125

Backhaus N (2011) Landscapes, spatial totalities or special regions? Procedia Soc Behav Sci 14:193-202, doi:10.1016/j.sbspro.2011.03.036

Bourassa SC (1991) The aesthetic of landscape. Belhaven Press, London

Brabyn L (2009) Classifying landscape character. Landsc Res 34(3):299-321, doi:10.1080/01426390802371202

Brush RO (1981) Landform and scenic preferences: a research note. Landsc Plan 8:301-306

Dramstad WE, Sundli Tveit M, Fjellstad WJ, Fry GLA (2006) Relationships between visual landscape preferences and map-based indicators of landscape structure. Landsc Urban Plan 78(4):465-474, doi:10.1016/j.landurbplan.2005.12.006

Ermolaev O (2003) Mathematical statistics for psychologists: a textbook. Moscow Psychological and Social Institute. Flint, Moscow (in Russian)

Gumilyov LN (1993) Ethnosphere: history of humans and history of nature. Ecopros, Moscow (in Russian)

Herzog TR, Maguire CP, Nebel MB (2003) Assessing the restorative components of environments. J Environ Psy 23(2):159-170

Hull RB IV, Reveli GRB (1989) Cross-cultural comparison of landscape scenic beauty evaluations: a case study in Bali. J Environ Psy 9(3):177-191, doi:10.1016/S0272-4944(89)80033-7

Hull RB, Stewart WP (1995) The landscape encountered and experienced while hiking. Environ Behav 27:404-426

Isachenko AG (1991) Landscape science and physical-geographical regionalization: a textbook for universities. Vysshaya shkola, Moscow (in Russian)

IUCN - International Union for Conservation of Nature (1969) National parks. http://www.iucn.org. Accessed 1 Jul 2014

Jones M (1991) The elusive reality of landscape. Concepts and approaches in landscape research. Norsk Geografisk Tidsskrift Nor J Geogr 45(4):229-244

Kaltenborn BP, Bjerke T (2002) Associations between environmental value orientations and landscape preferences. Landsc Urban Plan 59:1-11, doi:10.1016/S0169-2046(01)00243-2

Kaplan R (2001) The nature of the view from home: psychological benefits. Environ Behav 33(4):507-542

Kaplan R, Kaplan S (1989) The experience of nature: a psychological perspective. Cambridge University Press, New York

Kunikida D (1901) Musashino [The Musashi Plain]. Minyusha, Tokyo (in Japanese)

Lothian A (1999) Landscape and the philosophy of aesthetics: Is landscape quality inherent in the landscape or in the eye of the beholder? Landsc Urban Plan 44(4):177-198, doi:10.1016/S0169-2046(99)00019-5

Meshcheryakov AN (2010) Japan in the arms of space and time. Natalis, Moscow (in Russian)

Meshcheryakov AN (2012) The most beautiful: the nature of Japan in interpretation of Shiga Shigetaka. Hist Mod 1(15):111-137 (in Russian)

Nasar JL, Li M (2004) Landscape mirror: the attractiveness of reflecting water. Landsc Urban Plan 66:233-238

Nikolaev VA (2005) Landscape: aesthetics and design (a textbook). Aspect Press, Moscow (in Russian)

Ode Å, Tveit MS, Fry G (2008) Capturing landscape visual character using indicators: touching base with landscape aesthetic theory. Landsc Res 33 (1):89-117, doi:10.1080/01426390701773854

Okajima N, Petrova E, Petrova A (2010) The influence of Russian literature on two Japanese literary figures and the Japanese sense of scenic beauty. Proceedings of the 8th annual Hawaii international conference on arts \& humanities, Honolulu, pp 3135-3150, 13-16 Jan 2010

Orians GH (1986) An ecological and evolutionary approach to landscape aesthetics. In: Penning-Roswell EC, Lowenthal D (eds) Landscape meanings and values. Allen \& Unwin, London, pp 3-25
Petrova E, Aoki Y, Mironov Y, Petrova A, Furuya K, Matsushima H, Takayama N (2008a) Comparison of natural landscapes appreciation between Russia and Japan: methods of investigation. In: Raschi A, Trampetti S (eds) Management for protection and sustainable development: the fourth international conference on monitoring and management of visitor flows in recreational and protected areas. Ospedaletto, Pisa, pp 198-202

Petrova E, Aoki Y, Petrova A (2010) Landscape descriptions by Russian visitors to Japan until 1900. In: Kinda A, Komeie T, Minamide S, Mizoguchi S, Uesugi K (eds) Proceedings of the 14th international conference of historical geographers. Kyoto University, Kyoto University Press, Kyoto, pp 194-195

Petrova EG, Mironov YV, Petrova AA (2008b) National parks of Japan from the point of view of the Russians. Priroda (Nature) 11:28-39 (in Russian)

Purcell AT, Lamb RJ, Mainardi Peron E, Falchero S (1994) Preference or preferences for landscape? J Environ Psy 14(3):195-209, doi:10.1016/S0272-4944(94)80056-1

Sevenant M, Antrop M (2009) Cognitive attributes and aesthetic preferences in assessment and differentiation of landscapes. J Environ Manag 90(9):2889-2899, doi:10.1016/j.jenvman.2007.10.016

Staats H, Hartig T (2004) Alone or with a friend: a social context for psychological restoration and environmental preferences. J Environ Psy 24(2):199-211

Takayama N, Matsushima H, Petrova E, Ueda H, Nakajima T, Furuya K, Aoki Y (2012) Differences in environmental attitudes between Russia and Japan. In: Outdoor recreation in change: current knowledge and future challenges. Proceedings of the 6th international conference on monitoring and management of visitors in recreational and protected areas, Stockholm, pp 404-405, 21-24 Aug 2012

Tips WEJ, Savasdisara T (1986) The influence of the socio-economic background of subjects on their landscape preference evaluation. Landsc Urban Plan 13:225-230, doi:10.1016/0169-2046(86)90036-8

Ueda H, Nakajima T, Takayama N, Petrova E, Matsushima H, Furuya K, Aoki Y (2012) Landscape image sketches of forests in Japan and Russia. For Policy Econ 19:20-30, doi:10.1016/j.forpol.2012.01.002

Ulrich RS (1993) Biophilia, biophobia, and natural landscapes. In: Kellert SR, Wilson EO (eds) The biophilia hypothesis. Island Press, Washington, pp 73-137

Van den Berg AE, Koole SL, Van der Wulp NY (2003) Environmental preference and restoration: (How) are they related? J Environ Psy 23(2):135-146

Wherrett JR (2000) Creating landscape preference models using internet survey techniques. Landsc Res 25:79-96

Yang B, Brown TJ (1992) A cross-cultural comparison of preferences for landscape styles and landscape elements. Environ Behav 24(4):471-507

Yang BE, Kaplan R (1990) The perception of landscape style: a cross-cultural comparison. Landscape and Urban Planning 19:251-262, doi:10.1016/ 0169-2046(90)90024-V

\section{Submit your manuscript to a SpringerOpen ${ }^{\circ}$ journal and benefit from:}

- Convenient online submission

- Rigorous peer review

- Immediate publication on acceptance

- Open access: articles freely available online

- High visibility within the field

- Retaining the copyright to your article

Submit your next manuscript at $\boldsymbol{\wedge}$ springeropen.com 